\title{
Influências da Reposição de Estrógenos e Progestágenos na Ação do Hormônio de Crescimento em Mulheres com Hipopituitarismo
}

\begin{abstract}
RESUMO
O tratamento do hipogonadismo hipogonadotrófico na mulher adulta com hipopituitarismo inclui diversas alternativas terapêuticas de estrógenos e progestágenos, sendo a via oral a de menor custo e a de maior comodidade à paciente. A rota estrogênica oral, entretanto, exerce marcada influência sobre o eixo hormônio de crescimento/fator de crescimento insulina-símile número 1 (GH/IGF-1) nessas mulheres. O tratamento com estrógenos orais, concomitante ao uso de $\mathrm{GH}$ em pacientes com hipopituitarismo, antagoniza as ações biológicas do $\mathrm{GH}$ e agrava as anormalidades de composição corporal e o metabolismo em geral. Presume-se que o estrógeno oral iniba a secreção/produção de IGF-1 por meio de efeito de primeira passagem hepática, causando aumento da secreção de GH por intermédio de inibição do feedback negativo de IGF-1 em mulheres normais. Isso é demonstrado clinicamente por redução da massa magra, aumento da massa gorda, perfil lipídico aterogênico e prejuízo do bem-estar psicológico. Alguns estudos apontam que os progestágenos com ação androgênica revertem o efeito de diminuição dos níveis séricos de IGF-1 induzida pelos estrógenos orais. Os progestágenos neutros não apresentam esse efeito, porém, quanto maior a potência androgênica, maior será a reversão do efeito de diminuição de IGF-1. Na presente revisão da literatura, serão abordados os aspectos clínicos da reposição com estrógenos e progestágenos nas mulheres com hipopituitarismo, suas interações nas outras deficiências hormonais, bem como o impacto do uso de estrógenos sobre as ações metabólicas do GH. (Arq Bras Endocrinol Metab 2008; 52/5:901-916)
\end{abstract}

Descritores: Hipopituitarismo; Tratamento; Estrógenos; Progestágenos; IGF-1, IGFBPs

\begin{abstract}
The Influence of Estrogen and Progestogen Replacement on Growth Hormone Activity in Women with Hypopituitarism.

Treatment of hypogonadotropic hypogonadism in adult women with hypopituitarism can include a wide range of estrogen and progestogen treatment alternatives and oral administration is the route of least cost and greatest patient comfort. The oral estrogen route has a major impact on the growth hormone-insulin-like growth factor I (GH/IGF-1) axis. Oral estrogen therapy, when given concurrently with $\mathrm{GH}$ to patients with hypopituitarism, antagonizes the biological effects of $\mathrm{GH}$ treatment and aggravates the abnormalities of body composition and the metabolism in general. It is presumed that oral estrogen suppresses the secretion/production of IGF-1 by a hepatic first-pass mechanism, resulting in increased $\mathrm{GH}$ secretion by means of suppressing the IGF-1 negative feedback that is present in healthy women. This is clinically manifested in reduced lean body mass, increased fat mass, an atherogenic
\end{abstract}

revisão

\author{
Ana LÚCIA IsOTton \\ Maria Celeste O. Wender \\ Mauro A. Czepielewski
}

Serviço de Endocrinologia do Hospital de Clínicas de Porto Alegre. Programa de PósGraduação em Ciências Médicas: Endocrinologia da Faculdade de Medicina da Universidade Federal do Rio Grande do Sul (UFRGS), Porto Alegre, RS, Brasil. 
lipid profile and damage to psychological well-being. Some studies have indicated that progestogens with androgenic actions reverse the effect of reduced serum IGF-1 levels that is induced by the oral estrogens. Neutral progestogens do not exert this effect, however the stronger the androgenic potentialis, the more the effect of reduced IGF-1 will be reversed. This bibliographical review will deal with the clinical aspects of estrogen and progestogen replacement in women with hypopituitarism, their interactions with other hormone deficiencies and the impact of estrogen treatment on the metabolic actions of GH. (Arq Bras Endocrinol Metab 2008; 52/5:901-916)

Keywords: Hypopituitarism; Treatment; Estrogens; Progestogens; IGF-1, IGFBPS

\section{INTRODUÇÃO}

$\mathrm{O}$ HIPOPITUITARISMO CONSISTE da insuficiência parcial ou completa da secreção dos hormônios da hipófise anterior decorrentes de doença hipotalâmica ou hipofisária. Na criança, a deficiência múltipla da secreção desses hormônios é rara, contabilizando menos de três casos por milhão de pessoas por ano. No adulto, estima-se oito a dez novos casos por milhão de pessoas por ano (1). Suas causas são diversas. No adulto, particularmente, destacam-se os tumores hipofisários, cirurgia e/ou radiação sobre a hipófise, infarto hipofisário (apoplexia), tumores perihipofisários (meningiomas, gliomas, metástases), hipofisite linfocítica, trauma, infecção, abscessos, hemocromatose, doenças granulomatosas e histiocitose X (2).

Os sinais e sintomas são variáveis e dependem da causa, do tipo e da gravidade da deficiência hormonal. A reserva funcional da glândula é grande, e as manifestações clínicas do hipopituitarismo são evidentes quando ocorre comprometimento de pelo menos $75 \%$ do seu parênquima $(3,4)$.

As deficiências na secreção hormonal hipofisária manifestam-se na seguinte ordem: gonadotrofinas (hormônio luteinizante - LH; hormônio folículo-estimulante - FSH), somatotrofina $(\mathrm{GH})$, tireotrofina (hormônio tireoestimulante - TSH) e, mais tardiamente, corticotrofina (hormônio adrenocorticotrófico - ACTH). Invariavelmente, quando há deficiência de GH, há deficiência de dois ou mais hormônios hipofisários (1).

Os pacientes com lesões hipotálamo-hipofisárias podem apresentar sintomas associados às deficiências hormonais ou compressivos, que se caracterizam por cefaléia, alterações de campo visual e paralisia de nervos cranianos. As deficiências de hormônios adenoipofisários podem ter quadro clínico variável, de acordo com o grau de comprometimento da glândula e do tempo de evolução da doença (2).

\section{DEFICIÊNCIA GONADOTRÓFICA}

O hipogonadismo hipogonadotrófico é achado comum em indivíduos com afecções hipotálamo-hipofisárias, sendo a deficiência mais prevalente, após a de GH, podendo ocorrer de maneira isolada ou associada a outras deficiências (3).

$\mathrm{O}$ quadro clínico inclui fenômenos vasomotores (fogachos), amenorréia, infertilidade, redução da libido, sintomas urinários, redução da lubrificação vaginal, alterações do sono, diminuição da massa muscular, redução da massa óssea e dislipidemia (5).

O diagnóstico laboratorial é estabelecido por meio das dosagens de estradiol, de LH e de FSH, observandose níveis reduzidos de estradiol e gonadotrofinas em níveis baixos ou normais (5). Em algumas situações, recomenda-se ainda o teste de estímulo com hormônio liberador das gonadotrofinas $(\mathrm{GnRH})$, demonstrando-se ausência de resposta das gonadotrofinas ao estímulo (3).

$\mathrm{O}$ tratamento da deficiência gonadotrófica consiste da reposição de estrógenos e progestágenos. A disponibilidade de diversos hormônios sintéticos trouxe grande avanço para o tratamento de pacientes com esse distúrbio. Esses tratamentos, inicialmente, utilizaram hormônios de origem animal e, mais recentemente, diversos derivados sintéticos que procuram mimetizar a secreção hormonal normal. Mesmo com essas substâncias, a reposição dos diversos hormônios no hipopituitarismo ainda é bastante controversa, especialmente no que se refere ao eixo gonadotrófico do sexo feminino. Para as mulheres adultas, está disponível uma infinidade de substâncias para uso via oral e algumas para uso transdérmico. Mesmo assim, muitos derivados não per- 
mitem fracionamento de dose e não são fisiológicos quando se analisam seus diversos efeitos (5).

\section{TERAPIA DE REPOSIÇÃO COM ESTRÓGENOS E PROGESTÁGENOS}

Entre as diversas alternativas terapêuticas com estrógenos, a via oral é a mais utilizada por ter menor custo e pela comodidade para as pacientes. Entretanto, após a absorção intestinal, a passagem dos estrógenos pelo fígado induz o aumento da síntese de várias proteínas, como fatores de coagulação, angiotensinogênio e globulina carreadora dos esteróides sexuais (SHBG), o que pode causar hipercoagulabilidade, aumento da pressão arterial e diminuição da fração livre dos estrogênios circulantes, respectivamente (6). A vantagem da rota oral consiste da melhora do perfil lipídico, pois a passagem dos estrógenos pelo fígado faz que haja o aumento do high density lipoprotein cholesterol (HDL-colesterol) e a diminuição do low density lipoprotein cholesterol (LDL-colesterol), propiciando perfil lipoprotéico menos aterogênico. Esses efeitos, porém, não são observados com a rota transdérmica, que tem sido sugerida como mais fisiológica (7).

A estrogenioterapia pela rota oral tende a elevar os níveis de HDL, principalmente a fração de HDL2, associada à maior cardioproteção. Esse efeito é decorrente do bloqueio da enzima lipase hepática que converte HDL2 em HDL3. O estrogênio age também elevando os níveis de triglicerídeos, provavelmente por aumentar a produção hepática de very low density lipoprotein cholesterol (VLDL) e por diminuir os níveis séricos de LDL pelo aumento do número de receptores para esta lipoproteína, que passa a ser metabolizada em maior velocidade (8).

O Lipid Research Program verificou que a redução de $10,4 \%$ nos níveis de LDL levou à diminuição de $16 \%$ a $19 \%$ no risco de desenvolvimento de coronariopatia e que, para elevação de $10 \mathrm{mg} / \mathrm{dL}$ no HDL, há diminuição de $42 \%$ no risco cardiovascular (9). Esses dados são semelhantes aos do Framingham Heart Study, que, para essa elevação de HDL, observou $50 \%$ de redução no risco cardiovascular (10).

Existem várias formulações de estrógeno, e, na rota oral, as mais utilizadas são o etinilestradiol e os estrógenos eqüinos conjugados. Essas formulações, na rota oral, são convertidas predominantemente em estrona, cuja atividade biológica é menor que o estradiol. O estradiol natural (17 $\beta$-estradiol) tem baixa absorção oral e é inativado durante a passagem hepática. Para melhorar a absorção, deverá ser micronizado ou administrado em compostos derivados, como etinil, valerato, enantato e cipionato de estradiol. De todos esses compostos, o etinilestradiol é o composto de maior potência, por sofrer menor conversão à estrona. Os estrógenos eqüinos conjugados são a composição que mais sofre indução de síntese enzimática no fígado (11).

As dosagens de estrógeno oral variam e têm dependência individual. $\mathrm{O}$ objetivo é manter os níveis séricos de estradiol entre 30 e $50 \mathrm{pg} / \mathrm{mL}$, observados no início da fase folicular. Na prática, as doses variam de 0,3 a 1,25 mg para os estrógenos eqüinos conjugados, de 1,0 a $2,0 \mathrm{mg}$ para o estradiol micronizado, de 0,01 a $0,02 \mathrm{mg}$ para o etinilestradiol e de $2,0 \mathrm{mg}$ para o valerato de estradiol (2).

Quanto à bioequivalência dos estrógenos rotineiramente utilizados para a reposição, os adesivos que liberam $50 \mu \mathrm{g}$ de estradiol, por dia, equivalem a $0,625 \mathrm{mg}$ de estrogênios eqüinos conjugados e a $2 \mathrm{mg}$ de estradiol micronizado, por dia (11).

Na Tabela 1, estão apresentados os estrogênios utilizados na terapia de substituição hormonal, com doses e vias de administração existentes no mercado farmacêutico brasileiro.

Tabela 1. Derivados estrogênicos disponiveis no mercado brasileiro.

\begin{tabular}{|c|c|}
\hline Derivado & Dose \\
\hline \multicolumn{2}{|l|}{ Via oral } \\
\hline Estrogênios conjugados & $0,3-0,45-0,625-1,25 \mathrm{mg} / \mathrm{dia}$ \\
\hline $17 \beta$-estradiol micronizado & $1-2 \mathrm{mg} / \mathrm{dia}$ \\
\hline Valerato de estradiol & $1-2 \mathrm{mg} / \mathrm{dia}$ \\
\hline Hemisuccinato de estradiol & $1,5 \mathrm{mg} / \mathrm{dia}$ \\
\hline Estriol & 2-6 mg/dia \\
\hline \multicolumn{2}{|l|}{ Via transdérmica } \\
\hline Estradiol transdérmico & $25-50-100 \mu g / d i a$ \\
\hline Estradiol gel & 0-5-1,0-1,5-3,0 mg/dia \\
\hline \multicolumn{2}{|l|}{ Via nasal } \\
\hline Estradiol intranasal & $300 \mu \mathrm{g} / \mathrm{dia}$ \\
\hline \multicolumn{2}{|l|}{ Via subcutânea } \\
\hline Estradiol implante & 25 mg a cada 6 meses \\
\hline \multicolumn{2}{|l|}{ Via vaginal } \\
\hline Estrogênios conjugados & $0,625 \mathrm{mg} / \mathrm{dia}$ \\
\hline Estriol & $1-2 \mathrm{mg} / \mathrm{dia}$ \\
\hline Promestrieno & 10 mg/dia \\
\hline
\end{tabular}


A reposição estrogênica pela via transdérmica não apresenta primeira passagem hepática e isso faz que não ocorram os efeitos indesejáveis na coagulação ou na pressão arterial, embora não favoreça o perfil lipídico. A sua utilização, do ponto de vista fisiológico, propicia concentrações plasmáticas mais estáveis de estradiol e reduz sua conversão à estrona, quando comparada à rota oral. As doses também sofrem variação individual, oscilando entre 50 e $100 \mathrm{mg}$ de $17 \beta$-estradiol, duas vezes por semana (na via transdérmica) ou $1,5 \mathrm{~g}$ de gel (via percutânea) contendo 1,5 mg de estradiol hemi-hidratado (11).

A reposição com progestágenos é importante para evitar hiperplasia endometrial nas pacientes com útero intacto. Pode ser utilizada de maneira cíclica ou contínua. Na terapia cíclica, pode-se utilizar progestágenos, associados à estrogenioterapia, do $14^{\circ}$ ao $26^{\circ}$ dia do ciclo. As formulações são acetato de medroxiprogesterona 2,5 a $10 \mathrm{mg}$, progesterona micronizada 100 a 200 $\mathrm{mg}$, noretindrona $0,35 \mathrm{mg}$, gestodeno $0,75 \mathrm{mg}$ ou levonorgestrel $0,075 \mathrm{mg}$, entre outras (12).

A adição de progestágenos ao esquema de reposição estrogênica leva à diminuição de HDL e triglicerídeos. Os progestágenos parecem diminuir a produção de VLDL e aumentam a atividade da lipase hepática. Os efeitos sobre LDL são dependentes do seu grau de androgenicidade. Os derivados da 19-nortestosterona são os que mais revertem os efeitos das modificações estrogênicas benéficas das lipoproteínas. A progesterona micronizada tem sido apontada como a de ação mais neutra $(12,13)$.

$\mathrm{Na}$ Tabela 2, são observados os progestagênios mais freqüentemente utilizados e suas doses mínimas efetivas diárias para a proteção endometrial.

Tabela 2. Derivados de progestágenos disponíveis no mercado brasileiro.

\begin{tabular}{lc}
\hline Derivado & Dose \\
Via oral & \\
\hline Acetato de medroxiprogesterona & $1,5-2,5-5,0-10 \mathrm{mg} / \mathrm{dia}$ \\
\hline Acetato de ciproterona & $1-2 \mathrm{mg} / \mathrm{dia}$ \\
\hline Noretisterona & $0,35 \mathrm{mg} / \mathrm{dia}$ \\
\hline Acetato de noretisterona & $0,35-0,5-0,7-1,0 \mathrm{mg} / \mathrm{dia}$ \\
\hline Acetato de nomegestrol & $2,5-5,0 \mathrm{mg} / \mathrm{dia}$ \\
\hline Didrogesterona & $5,0-10 \mathrm{mg} / \mathrm{dia}$ \\
\hline Dienogest & $2,0 \mathrm{mg} / \mathrm{dia}$ \\
\hline Norgestimato & $9 \mu \mathrm{g} \mathrm{3/3} \mathrm{dias}$ \\
\hline Progesterona micronizada & $100-200-300 \mathrm{mg} / \mathrm{dia}$ \\
\hline Trimegestona & $0,5 \mathrm{mg} / \mathrm{dia}$ \\
\hline Via transdérmica & $140-170-250 \mu \mathrm{g} / \mathrm{dia}$ \\
\hline Acetato de noretisterona & $100-200-300 \mathrm{mg}$ \\
\hline Via vaginal & \\
\hline Progesterona micronizada & \\
\hline
\end{tabular}

No tratamento do climatério, a terapia de reposição estroprogestagênica (TREP) tem sido alvo de muitas controvérsias. Desde a publicação dos dados de estudos, como o Heart and Estrogen/Progestin Replacement Study (HERS), as indicações da TREP modificaram drasticamente (14). Esse estudo avaliou 2.763 mulheres com doença coronariana prévia, pós-menopáusicas idosas, mostrando aumento no número de eventos coronarianos durante o primeiro ano de uso e benefício cardiovascular ausente ao longo dos anos de acompanhamento (14,15). O mesmo estudo demonstrou também que a terapia estroprogestagênica causou aumento do número de casos de tromboembolismo venoso nessas mulheres $(14,16)$.

Quatro anos mais tarde, em julho de 2002, foram publicados os resultados do Women's Health Initiative (WHI), que avaliou 16.608 mulheres pós-menopáusicas, sem evidência de coronariopatia, com útero intacto, média de idade de 63 anos e que utilizaram 0,625 $\mathrm{mg}$ de estrogênios eqüinos conjugados e $2,5 \mathrm{mg}$ de acetato de medroxiprogesterona ou placebo. O excesso de risco absoluto por 10 mil pessoas por ano atribuível a esse esquema de reposição foi de sete vezes mais eventos cardiovasculares, oito mais casos de acidente vascular cerebral (AVC), oito mais casos de câncer de mama invasor e oito mais casos de embolia pulmonar. A redução de risco absoluto por 10 mil pessoas por ano foi de seis menos casos de câncer colorretal e cinco menos casos de fratura de quadril (17).

Em agosto de 2003, foram publicados os resultados do The Million Women Study Group, que avaliou 1.084.110 mulheres e investigou o efeito de tipos específicos de TREP e a incidência de câncer de mama. De todas as mulheres estudadas, evidenciou-se 9.364 casos de câncer de mama invasor e 637 mortes por câncer de mama, em 2,6 e 4,1 anos de seguimento, respectivamente. As usuárias correntes da TREP tiveram risco aumentado de $66 \%$ de desenvolver câncer de mama e de $22 \%$ de morte em relação às mulheres que nunca fizeram uso dessa terapia. Entre as usuárias correntes, em 2,6 anos de seguimento, as que utilizaram estrogênio isoladamente tiveram $30 \%$ a mais de risco de câncer de mama invasor. As pacientes que utilizaram a combinação estroprogestagênica e as que usaram tibolona tiveram, respectivamente, $100 \%$ e $45 \%$ a mais de chance de desenvolvimento dessa patologia.

Entretanto, uma questão ainda não respondida é se a hormonioterapia causa câncer de mama ou é agente promotor da carcinogênese em tumores já existentes. 
Os achados que suportam o impacto de tumores preexistentes incluem a concordância entre todos os estudos de que não há aumento de risco em usuárias passadas e de que o rápido diagnóstico de câncer de mama inicia-se dentro de poucos anos após o início da terapia (18).

Em fevereiro de 2004, o Instituto Nacional de Saúde dos Estados Unidos (NIH) solicitou que fosse suspenso o braço do WHI que avaliou o uso de estrogenioterapia isolada versus placebo, em 11 mil pacientes pós-menopáusicas histerectomizadas. Analisando os dados após quase sete anos de seguimento, os pesquisadores concluíram que o uso exclusivo de estrógeno não parece afetar a incidência de problemas cardíacos, ou seja, não aumenta nem diminui o risco desse tipo de problema. Paralelamente, houve aumento do risco de AVC, com RR de 1,39 (IC 95\% 1,10-1,77) e redução do risco de fratura de colo de fềmur $(\mathrm{RR}=$ 0,61, IC 95\% 0,41-0,91). Não houve aumento do risco de câncer de mama $(\mathrm{RR}=0,77$, IC 95\% 0,59-1,01) nestes sete anos de estudo (19).

A Sociedade Norte-Americana de Menopausa (NAMS), em setembro de 2003, posicionou-se sobre o uso de TREP em mulheres peri e pós-menopáusicas, salientando que estrógenos e progestágenos não deveriam ser utilizados para prevenção primária ou secundária de doença cardiovascular ou AVC. Além disso, reiterou a idéia de que a principal indicação para o uso da TREP sistêmica consiste do tratamento de sintomas vasomotores moderados a graves. Os sintomas locais, como dispareunia, ressecamento vaginal e vaginite atrófica, devem ser tratados com estrogenioterapia tópica (20).

Os dados de estudos como WHI e HERS não devem ser extrapolados para mulheres com falência ovariana prematura (menos de 40 anos), menopausa prematura ou que iniciaram TREP naquele momento. $\mathrm{O}$ risco/benefício parece ser mais favorável para essas mulheres. Uma explicação plausível para esses dados reside no fato de que o WHI e o HERS estudaram pacientes com mais idade, com média de idade de 63 e 67 anos, respectivamente. Além disso, no caso do estudo HERS, as mulheres estudadas tinham doença coronariana conhecida e, das pacientes do WHI, 36\% tinham hipertensão, $13 \%$ apresentavam dislipidemia, $4,4 \%$ tinham diabetes, $10,5 \%$ eram fumantes e $34,2 \%$ apresentavam sobrepeso (20).

Em outubro de 2004 e março de 2007, a NAMS reiterou as informações citadas anteriormente e ressaltou que as pacientes com menopausa e falência ovariana pre- maturas apresentam precocemente osteoporose e doença coronariana. Entretanto, não está evidenciado em ensaios clínicos se a estrogenioterapia isolada ou combinada com progestágeno reduziria a morbimortalidade referente a essas condições $(21,22)$.

Essas sugestões devem ser mais importantes para as pacientes com hipogonadismo hipogonadotrófico associado ao pan-hipopituitarismo. Nessas mulheres, a carência estrogênica provoca diversas e graves alterações clínicas que podem reduzir sua expectativa de vida $(4,23,24)$. Além disso, a escolha da via de administração oral, tanto de estrógenos quanto de progestágenos, pode interferir na absorção, ação, metabolização e efeitos clínicos das reposições de outros hormônios, especialmente tiroxina, glicocorticóides e GH (1).

\section{INTERAÇÕES DA REPOSIÇÃO COM ESTRÓGENOS E PROGESTÁGENOS NAS OUTRAS DEFICIÊNCIAS HORMONAIS}

No que se refere ao eixo hipotálamo-hipófise-tireóide, é bem conhecida a elevação dos níveis de thyroxin-bindingglobulin (TBG) induzida pelos estrógenos, diminuindo, portanto, a fração de hormônio livre. Assim, pacientes em uso de terapia de reposição estrogênica ou em uso de anticoncepcionais orais poderão apresentar aumento na necessidade de tiroxina $(2,25,26)$. Arafah demonstrou aumento da TBG de 50\% em mulheres utilizando estrógenos eqüinos conjugados na dose de $0,625 \mathrm{mg} /$ dia, tanto naquelas com função tireoidiana normal quanto nas pacientes com hipotireoidismo (26). Esse aumento nos níveis de TBG induzido pela estrogenioterapia é dose-dependente e ocorre quando a via de administração é oral, isoladamente ou associada com progestágeno. O estradiol transdérmico não aumenta as concentrações da TBG, evidenciando efeito de primeira passagem hepática $(25,26)$. Em mulheres normais, o aumento da TBG induzido pela estrogenioterapia oral provoca elevação da tiroxina (T4) total sérica sem modificação nos níveis de T4 livre. Essa alteração é importante para a monitorização da reposição de $\mathrm{T} 4$ desses pacientes, que deve ser realizada por meio da medida de T4 livre e não da T4 total.

Os estrógenos orais aumentam a corticosteroid binding globulin (CBG) e, portanto, resultam níveis falsamente elevados de cortisol na maior parte dos radioimunoensaios de rotina (que medem o cortisol total, e não a fração livre). Resultados falso-positivos são vistos em $50 \%$ das mulheres que fazem uso de contra- 
ceptivos orais. Além disso, o aumento da CBG é considerado medida do grau de "estrogenicidade" dos contraceptivos orais. Esse aumento da CBG é dosedependente dos estrógenos, e o componente progestacional parece não interferir nesse aumento (27-30).

A estrogenioterapia oral produz queda significativa nos níveis séricos de IGF-1, e a dose de GH deve ser aumentada para manter níveis de IGF-1 adequados (31). Assim, a rota estrogênica oral parece antagonizar as ações biológicas do $\mathrm{GH}$, agravando as anormalidades de composição corporal e o metabolismo em geral (31-33). A via estrogênica transdérmica, entretanto, não modifica os níveis séricos de IGF-1, podendo até produzir aumento (34-36). O emprego de progestágenos com efeito androgênico pode reverter o efeito de diminuição de IGF-1 induzido pelos estrógenos orais. Entre essas substâncias, serão incluídas a medroxiprogesterona, o desogestrel e a noretisterona, em ordem crescente de "androgenicidade" e de aumento dos níveis séricos de IGF-1 (37).

\section{ESTRÓGENOS E AÇÃO DO GH}

\section{Efeitos estrogênicos sobre o eixo GH/IGF-1}

O GH regula o crescimento e a composição corporal por meio de um processo complexo que combina ações mitogênicas e metabólicas, que utilizam mecanismos dependentes e independentes de IGF-1. O fígado tem papel importante nesse processo metabólico, pois é um órgão-alvo na ação do $\mathrm{GH}$, responsável pelos níveis séricos de IGF-1 e também órgão-alvo dos hormônios sexuais $(38)$.

Os estrógenos são responsáveis pelo desenvolvimento sexual secundário e têm papel fundamental na função reprodutiva feminina. Existe relação estreita entre os estrógenos e o GH na regulação do crescimento e do desenvolvimento na puberdade (39).

A interação regulatória dos estrógenos sobre o GH pode ocorrer em vários níveis, como secreção, clearance e ação. A maioria dos estudos aborda os efeitos estrogênicos na secreção do GH em nível hipotalâmico e hipofisário. Todavia, existem fortes evidências de que os estrógenos modulam a ação do $\mathrm{GH}$, independente de sua secreção, por meio de mecanismos hepáticos (38). Essas observações advêm do fato de que os estrógenos administrados pela via oral levam à perda na ação metabólica do GH e de que os estrógenos influenciam a resposta da terapia com $\mathrm{GH}$ em adultos (31).
Em mulheres pós-menopáusicas, tanto os estrógenos endógenos quanto os exógenos exercem marcada influência sobre o eixo GH/IGF-1. Ho e cols. demonstraram que a secreção espontânea de GH e os níveis séricos de IGF-1 são inferiores em mulheres pós-menopáusicas quando comparadas às pré-menopáusicas e que estes hormônios correlacionam-se positivamente com os níveis de estradiol livre (40).

$\mathrm{O}$ GH circula no plasma ligado à proteína ligadora do hormônio de crescimento (GHBP), sendo o fígado a maior fonte dessa proteína ligadora. A GHBP altera a distribuição e a farmacocinética do GH e parece modular a ação deste (4l).

\section{Rota de administração}

A rota de administração dos estrógenos tem impacto importante sobre os níveis séricos de IGF-1, tanto em mulheres pós-menopáusicas quanto em pacientes com hipopituitarismo $(31,36,42)$.

A terapia com estrógeno oral em mulheres pósmenopáusicas aumenta a secreção de GH e de GHBP e diminui os níveis séricos de IGF-1. As seqüelas metabólicas do uso da administração estrogênica oral, amplamente utilizada em nosso meio, incluem a supressão da oxidação lipídica e as mudanças de composição corporal, prejudicando a ação do $\mathrm{GH}(31,32,43)$.

Presume-se que o estrógeno oral iniba a secreção/ produção de IGF-1 por meio de um efeito de primeira passagem hepática, causando, em mulheres normais, aumento da secreção de GH pela inibição do feedback negativo de IGF-1 $(38,44)$.

A IGF-1 circula no plasma em $75 \%$ das vezes por meio de um complexo ternário com proteína ligadora número 3 do IGF-1 (IGFBP-3) e subunidade ácidolábil (ALS). A IGFBP-3 não apresenta modificações significativas com o uso de estrógeno oral (35).

Estudos com a rota estrogênica transdérmica, todavia, demonstraram efeitos diversos nos níveis séricos de GH e de IGF-1. A administração de $17 \beta$-estradiol transdérmico em mulheres $\mathrm{GH}$-deficientes demonstrou ausência de efeito sobre as concentrações de $\mathrm{GH}$ e GHBP e ausência de efeito ou aumento nos níveis séricos de IGF-1. Esses achados são consistentes com a hipótese previamente descrita de que os estrógenos transdérmicos não sofrem o efeito de primeira passagem hepática, entrando diretamente na circulação sistêmica, e, portanto, não trazem repercussões sobre as concentrações de IGF-1 e de GH. Os níveis séricos de 
IGFBP-3 também não sofrem modificações com o uso de estrógenos transdérmicos (35).

Weissberger, Ho e Lazarus estudaram o impacto da rota estrogênica sobre o eixo GH/IGF-1 em mulheres pós-menopáusicas, em que administraram $20 \mu \mathrm{g}$ de etinilestradiol oral e $100 \mu \mathrm{g}$ de $17 \beta$-estradiol transdérmico. Verificaram as concentrações de GH e IGF-1 no estado basal e dois meses após o início da terapia. Ambos os regimes resultaram reduções semelhantes de $\mathrm{LH}$ e $\mathrm{FSH}$, indicando bioequivalência estrogênica. O uso da rota oral resultou aumento dos níveis séricos de $\mathrm{GH}$ e redução de IGF-1. A rota transdérmica não afetou as concentrações de GH e induziu pequeno aumento, porém significativo, nos níveis séricos de IGF-1 (36).

Bellantoni e cols. compararam o efeito da rota estrogênica oral e transdérmica sobre os níveis séricos de GH, IGF-1 e IGFBP-3 em mulheres pós-menopáusicas jovens (menos de 62 anos) e idosas (mais de 62 anos). O estrógeno oral aumentou a secreção espontânea de $\mathrm{GH}$, diminuiu os níveis séricos de IGF-1 e não alterou as concentrações de IGFBP-3. O estrógeno transdérmico, entretanto, não alterou a secreção de $\mathrm{GH}$ e IGF-1, mas reduziu os níveis de IGFBP-3 em pós-menopáusicas idosas (34).

A maioria dos investigadores confirmou o efeito de diminuição de IGF-l da rota estrogênica oral (31,36,42,44-46). Entretanto, houve relatos de ausência de efeito (47) e até redução de IGF-1 (48). Estudos em ratos demonstraram que a administração estrogênica oral inibe a expressão hepática do RNA mensageiro (49). Assim, a produção hepática de IGF-l é suprimida pelo efeito farmacológico do estradiol oral. O mecanismo de primeira passagem hepática também explica as diferenças de efeito dos estrógenos orais e transdérmicos sobre os níveis séricos de GHBP, pois o fígado é rico em receptores para $\mathrm{GH}$, e a GHBP é derivada deste (36).

Assim, a redução de IGF-1 induzida por estrógenos orais pode ser mais importante em pacientes com hipopituitarismo, uma vez que nelas não ocorre elevação compensatória do $\mathrm{GH}$.

A Figura 1 demonstra que o aumento da secreção de GH não é decorrente de efeito estrogênico, mas secundário à perda do feedback negativo do IGF-1 sobre a hipófise (36).

Alguns estudos apontam que os progestágenos com ação andogênica revertem o efeito de diminuição dos níveis séricos IGF-1 induzida pelos estrógenos orais
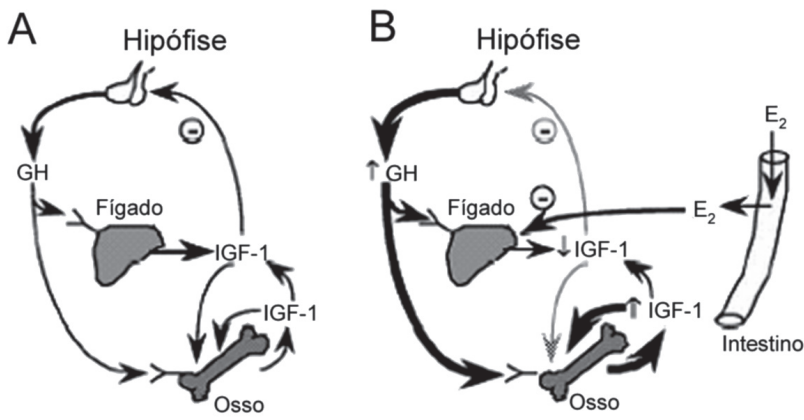

$\mathrm{E}_{2}=$ estradiol (Adaptado de Leung e cols., Endocrine Reviews, 2004 (38)).

Figura 1. Ação de $\mathrm{GH}$ e $\mid \mathrm{GF}-1$ e efeito de estrógeno oral. A) Conceitos atuais sobre a ação do GH mediada por IGF-1. Tecidos periféricos, como ossos, respondem aos efeitos combinados do IGF-1 circulante derivado do fígado (endócrino) e do IGF-1 gerado localmente (parácrino). Ambas as fontes contribuem para a inibição do feedback à liberação de $\mathrm{GH}$ da hipófise; B) Impacto da administração de estrógeno oral, que inibe a produção hepática de IGF-1 para reduzir o IGF-1 circulante. A perda de inibição do feedback resulta estimulação da secreção de $\mathrm{GH}$, o que poderia estimular tecidos periféricos, como ossos e músculos, e melhorar a ação parácrina do IGF-1, levando a níveis maiores de procolágeno circulante ou aumento de massa magra. Como isso não ocorre, sugere-se que o IGF-1 endócrino seja o regulador mais importante da estimulação dos tecidos periféricos do que o IGF-1 local.

$(50,51)$. Os progestágenos neutros não apresentam esse efeito, porém quanto maior a potência androgênica, maior será a reversão do efeito de diminuição de IGF-1 (51).

\section{Formulações estrogênicas}

Os tipos de estrógenos utilizados na maioria dos estudos antes citados não são idênticos $(36,44,52,53)$. Conseqüentemente, os dados não excluem totalmente a possibilidade de que os efeitos contrastantes entre preparações estrogênicas orais e transdérmicas reflitam diferenças químicas intrínsecas. Estudos demonstram que a indução de síntese protéica pelo etinilestradiol parece ser aparentemente maior do que sua habilidade na supressão das gonadotrofinas, comparando com outras formulações estrogênicas. Esses efeitos hepáticos não foram totalmente eliminados quando o etinilestradiol foi administrado pela via vaginal $(54,55)$.

Kelly e cols. compararam os efeitos de três formulações estrogênicas orais (etinilestradiol $20 \mu \mathrm{g}$, estrogênios eqüinos conjugados $1,25 \mathrm{mg}$ e valerato de estradiol $2 \mathrm{mg}$ ), e todas elas induziram queda nos níveis de $\mathrm{LH}$ e FSH, com elevações dos níveis séricos de SHBG e angio- 
tensinogênio. As concentrações de GHBP também aumentaram e os três tipos de estrógenos reduziram significativamente os níveis de IGF-1. As concentrações médias de $\mathrm{GH}$, em 24 horas, aumentaram durante os tratamentos, observando-se relação inversa com as concentrações de IGF-1. Portanto, infere-se que esse aumento das concentrações de $\mathrm{GH}$ seja secundário à inibição do feedback negativo pelo IGF-1. O aumento das concentrações de GHBP com os estrógenos orais indica que essa proteína sofre indução hepática de maneira similar à que ocorre com o angiotensinogênio e a SHBG (42).

Friend e cols. demonstraram que as concentrações séricas de IGF-1 reduziram significativamente após a administração de estrógenos transdérmicos em doses suprafisiológicas (sete vezes maior que a dose terapêutica), acompanhadas pelo aumento nas concentrações de GH. Essas alterações são indistinguíveis daquelas que ocorrem após a administração de $2 \mathrm{mg}$ de estradiol oral, indicando que a alta concentração de estrógeno é que leva à inibição da síntese hepática de IGF-1, independente da circulação portal ou sistêmica (46).

\section{Efeitos sobre as IGFBP}

Até o momento, foram identificadas seis IGFBP. A IGF-1 circula no plasma ligada quase totalmente à IGFBP-3 e à ALS, ambas reguladas pelo GH. E esse complexo ternário altera a farmacocinética, a distribuição e a biodisponibilidade do IGF-l (56). A ALS é sintetizada exclusivamente pelo fígado, enquanto muitos tecidos periféricos sintetizam IGFBP-3 (57). A ALS, à semelhança do que ocorre com o IGF-1, sofre efeito da rota e da dose dos estrógenos e não é afetada pelo tipo de estrógeno (58).

Os efeitos dos estrógenos orais sobre a IGFBP-3, entretanto, são menos consistentes. Alguns estudos relatam efeito supressivo dos estrógenos orais sobre os níveis séricos de IGFBP-3, e esse efeito é semelhante nos mais variados tipos de estrógenos, tanto em mulheres pósmenopáusicas quanto em hipogonádicas $\mathrm{GH}$-deficientes $(51,58)$. Outros estudos, entretanto, demonstraram ausência de efeito dos estrógenos orais sobre a IGFBP-3 $(59,60)$. As razões para essas diferenças não estão totalmente claras, mas a IGFBP-3 hepática pode ser diluída por outros tecidos periféricos, os quais também são fontes dessa proteína ligadora, principalmente se não estiver ligada ao complexo ternário (56). A redução observada nos valores séricos de IGFBP-3 pelos estrógenos orais poderia advir secundariamente de redução primária de IGF-1 e ALS. A IGFBP-3 é sintetizada nas células de
Kupffer, enquanto o IGF-1 e a ALS são sintetizados pelos hepatócitos, o que poderia explicar essa diferença na regulação pelos estrógenos (57).

Em mulheres hipogonádicas e GH-deficientes, os estrógenos orais reduzem significativamente tanto a IGFBP-3 quanto a ALS, indicando que esses efeitos são independentes do GH (58). Assim sendo, os estrógenos exercem efeito inibitório em todos os componentes do complexo ternário do IGF-1, relacionados à dose $\mathrm{e}$ à via de administração.

A proteína ligadora número 1 do IGF- 1 (IGFBP- 1 ) também é proteína sintetizada em nível hepático, regulada pela insulina e pelo estado nutricional do paciente. Liga-se à fração de IGF-1 livre e atenua o efeito hipoglicemiante do fator de crescimento (61). Os estrógenos exercem efeito dependente da rota sobre os níveis circulantes de IGFBP-1, uma vez que a rota oral aumenta seus níveis $(44,51,53,62)$. Esse aumento da IGFBP-1 levará à redução da taxa de IGF-1 livre, reduzindo a sua atividade $(44,53,62)$.

As proteínas ligadoras números 2, 4, 5 e 6 do IGF-1 (IGFBP-2, IGFBP-4, IGFBP-5 e IGFBP-6) são sintetizadas em nível extra-hepático. A IGFBP-5, derivada do tecido ósseo, é regulada pelo GH. Pouco se sabe sobre as interações regulatórias entre os estrógenos e essas proteínas ligadoras (63).

\section{Efeitos biológicos}

Os três maiores componentes do eixo GH/IGF-1 (GH, IGF-1 e GHBP) são afetados pela administração de estrógenos orais. Recentes estudos também têm analisado se os estrógenos exercem efeitos biológicos dependentes da rota (38).

\section{Osso e tecido conjuntivo}

$\mathrm{O}$ GH promove o crescimento de vários tecidos, incluindo o conjuntivo e o ósseo. Durante o tratamento com GH ocorre aumento em pró-peptídios para colágeno tipo I e tipo III, estimulando a formação óssea e a síntese de colágeno $(64,65)$. O GH também eleva a osteocalcina sérica, que é um marcador de formação óssea (65). Esses efeitos anabólicos do GH parecem ser mediados pelo IGF-1 em função de receptores específicos de IGF-1 presentes nos fibroblastos e osteoclastos $(66,67)$. O IGF- 1 estimula também a síntese de colágeno e a replicação dessas células (68).

Os marcadores de tecido conjuntivo e ósseo são influenciados pela rota de administração estrogênica. Os 
níveis séricos de osteocalcina, procolágeno tipos I e III, assim como o que ocorre com os níveis séricos de IGF-1, declinam após o uso de estrógeno oral, apesar de o aumento dos níveis circulantes de GH. Esses marcadores, entretanto, aumentam durante a estrogenioterapia transdérmica (69).

A dissociação do eixo GH/IGF-1 induzida pelos estrógenos orais sinaliza a importância do IGF-1 no controle do crescimento tissular periférico. De acordo com a hipótese da somatomedina, a queda nos níveis séricos de IGF-1 induzida pelos estrógenos orais será acompanhada de redução da atividade metabólica tissular periférica, visibilizada por meio da redução dos marcadores dos tecidos ósseo e conjuntivo (70).

\section{Metabolismo da glicose}

O estímulo da secreção de GH induzida pela estrogenioterapia oral pode levar a prejuízos no metabolismo dos carboidratos, pois o GH causa resistência insulínica $(36,42)$.

Estudos prévios com contraceptivos orais demonstraram associação com a perda da tolerância à glicose, hiperinsulinemia e redução da sensibilidade insulínica $(71,72)$.

A maioria dos estudos com TREP em mulheres pósmenopáusicas para avaliar o metabolismo dos carboidratos apresentou resultados conflitantes, alguns demonstrando deterioração da tolerância à glicose e à hiperinsulinemia $\mathrm{e}$ outros sem mudanças significativas (73-75).

Estudos epidemiológicos com TREP em mulheres pós-menopáusicas demonstraram redução da glicemia de jejum e dos níveis séricos de insulina. Os dados conflitantes estavam relacionados ao uso de doses e formulações diversas de TREP, bem como à falha da avaliação do efeito estrogênico isolado ou combinado com progestágenos (76).

O impacto da rota estrogênica sobre o metabolismo dos carboidratos apresenta importância clínica relevante. Estudos com estrógenos orais demonstraram aumento da secreção de GH em mulheres pós-menopáusicas, independente da formulação estrogênica. $\mathrm{O}$ uso de estrógenos transdérmicos não alterou os níveis de GH. E como o GH piora a ação da insulina, é importante ressaltar que a via de administração estrogênica pode ter resultados diversos sobre o metabolismo dos carboidratos $(36,42)$.

O'Sullivan e Ho, por meio da técnica do clampe euglicêmico hiperinsulinêmico para avaliar a sensibili- dade insulínica, observaram que a taxa média de infusão de glicose para manter euglicemia foi discretamente menor durante o uso de estrógeno oral do que durante o de estrógeno transdérmico, porém não significativa. Todavia, durante o uso de estrógeno transdérmico, a concentração média de ácidos graxos livres foi suprimida pela insulina. Esses dados sugerem que a insulina iniba a lipólise de maneira mais eficaz durante o uso de estrógenos transdérmicos e, assim sendo, os níveis de ácidos graxos livres refletem a ação da insulina do tecido adiposo. Comparada à rota oral, a estrogenioterapia transdérmica está associada à melhora tênue, mas significativa, da ação da insulina sobre o metabolismo lipídico. E a rota da terapia de reposição estrogênica parece não ter impacto maior sobre o metabolismo da glicose em mulheres pós-menopáusicas (77).

Estudos com mulheres jovens em uso de anticoncepcional oral (ACO) apontam efeito negativo de doses mais potentes de estrógenos $(20$ a $30 \mu \mathrm{g}$ de etinilestradiol) sobre a sensibilidade insulínica. Essas mulheres exibiram $30 \%$ a $40 \%$ menos de sensibilidade à insulina $(78,79)$. Perseghin e cols. observaram que o grupo tratado com estrógenos apresentou níveis elevados de ácidos graxos livres, triglicerídeos e $\beta$-hidroxibutirato em relação ao grupo-controle (78). Como o ACO reduz IGF-1 e aumenta os níveis de GH, alguns estudos sugerem que o desenvolvimento de insulino-resistência seja mediado pelo $\mathrm{GH}(43,80)$.

\section{Oxidação de substrato}

Estudos em pacientes GH-deficientes adultos utilizando terapia de substituição com GH demonstraram que este tem papel importante na regulação da oxidação de substrato e da composição corporal (81-83). O estímulo da oxidação lipídica e da síntese protéica durante o uso de GH leva à queda progressiva na massa gorda $\mathrm{e}$ ao aumento da massa magra em indivíduos adultos GH-deficientes (82).

$\mathrm{O}$ GH estimula o gasto energético e o metabolismo oxidativo da gordura, mecanismos importantes para a redução da massa gorda. O fígado tem papel importante no metabolismo da gordura e é onde os ácidos graxos são oxidados, após a liberação dos locais de estoque periférico de gordura, em maior proporção $(82,83)$.

Os estrógenos administrados pela rota oral podem suprimir a oxidação lipídica, por meio de mecanismo de primeira passagem hepática. O'Sullivan e cols. compararam os efeitos da terapia com estrógenos oral e trans- 
dérmico sobre a oxidação do substrato, em um estudo com 18 pacientes pós-menopáusicas, randomizado e com crossover. Não foram identificadas diferenças significativas sobre o gasto energético e a oxidação lipídica basal entre os grupos. Entretanto, quando comparada à rota transdérmica, a rota oral de administração estrogềnica suprimiu a oxidação lipídica em nível superior. A supressão da oxidação lipídica foi acompanhada de estímulo na oxidação de carboidratos (84).

Não está bem definido em qual proporção a oxidação lipídica é reduzida pelos estrógenos orais. Um possível mecanismo envolvido decorre do aumento nos níveis de GHBP, o qual poderia atenuar os efeitos estimulatórios do $\mathrm{GH}$ endógeno sobre a oxidação de gorduras. $\mathrm{O}$ achado de perda da sensibilidade insulínica durante o tratamento com estrógeno oral constitui argumento contrário a essa possibilidade. Outro mecanismo pode envolver efeito direto do estrógeno sobre o fígado, que é o maior sítio do metabolismo dos ácidos graxos. Estudos in vitro demonstraram que as concentrações farmacológicas de estrógenos reduzem a cetogênese (produto da oxidação dos ácidos graxos) e aumentam a incorporação de ácidos graxos em triglicerídeos (85). Esses achados estão de acordo com as observações clínicas de que os estrógenos orais estimulam a síntese hepática de triglicerídeos e aumentam os níveis séricos destes (86).

\section{Composição corporal}

O'Sullivan e cols. estudaram mulheres pós-menopáusicas, que foram randomizadas para receber estrógeno oral e estrógeno transdérmico, e observaram que, após seis meses, não houve diferença significativa de peso corporal entre e dentro dos grupos. Porém, observaram-se diferentes efeitos na massa magra e na massa gorda entre os dois grupos de tratamento. A terapia oral, comparada à transdérmica, levou ao aumento significativo da massa gorda de $1,2 \mathrm{~kg}$, equivalente a $5 \%$ de mudança na gordura corporal. Não houve diferença significativa durante o tratamento com estrógenos transdérmicos. No grupo oral, também ocorreu perda na massa magra, equivalente a $3 \%$ de mudança comparada à observada no grupo transdérmico. Essa redução significativa da massa magra foi de $0,8 \pm 0,3 \mathrm{~kg}$ com o grupo oral, e houve pequeno aumento e não significativo da massa magra durante a fase transdérmica (84).

Especula-se que a supressão hepática prolongada de IGF-1 pelo uso de estrógenos orais acarrete perda na massa protéica e supressão da oxidação lipídica, com conseqüente acúmulo de gordura corporal. As diferentes vias de administração de estrógenos induziram mudanças significativas na composição corporal, sem modificar o peso corpóreo. A mudança na massa magra também aponta a importância nos níveis séricos de IGF-1 na regulação positiva do anabolismo $(83,84)$.

Estudos que abordam o efeito dos estrógenos sobre o peso e a gordura corporais na pós-menopausa apresentam resultados conflitantes, principalmente em razão do viés de seleção das pacientes e, também, em virtude das diferenças comportamentais e sociodemográficas entre usuárias e não-usuárias (87-91). Todavia, dois estudos prospectivos randomizados apontaram achados diferentes na gordura corporal total, apesar de utilizarem métodos similares para quantificá-la $(92,93)$. Existe consenso entre a maioria dos estudos de que o tratamento com estrógenos induza à redistribuição da gordura corporal do tronco para as áreas corporais inferiores, explicadas pelas diferenças de sensibilidade do tecido adiposo aos estrógenos e, possivelmente, mediadas pela atividade da lípase lipoprotéica, enzima responsável pela hidrólise de triglicerídeos a ácidos graxos livres $(87,93)$.

\section{Metabolismo das lipoproteínas e marcadores inflamatórios}

O GH regula o metabolismo das lipoproteínas e tem influência sobre os níveis circulantes de marcadores inflamatórios (94). Os efeitos dos estrógenos sobre o metabolismo das lipoproteínas e sobre os marcadores inflamatórios são dependentes da via de administração destes (95).

O uso de estrógenos orais reduz o colesterol total e o LDL-colesterol, aumentando os níveis de HDLcolesterol e de triglicerídeos. Essas mudanças decorrem do aumento da expressão do receptor hepático de LDL, acarretando o catabolismo do LDL-colesterol, e estimulam a secreção hepática de triglicerídeos ricos em VLDL (95). Esses efeitos dos estrógenos orais sobre o metabolismo do LDL podem ser mediados pelo aumento da secreção de GH. Estudos com roedores demonstraram que os estrógenos regulam o receptor hepático de LDL apenas na presença de GH. Estudos in vitro com fígado humano observaram que o GH estimula a expressão desse receptor $(96,97)$. O GH aumenta o catabolismo do LDL e da apolipoproteína B por meio desse mecanismo $(96,97)$, que estimula a síntese hepática de VLDL e a secreção de triglicerídeos (98). O GH melhora o turnover do 
VLDL e do LDL, o que pode explicar os aumentos de HDL e LDL $(94,99)$.

Os estrógenos administrados pela rota transdérmica exercem efeitos modestos sobre o colesterol total, LDL e HDL. Entretanto, ocorre queda nos níveis séricos de triglicerídeos, mesmo na ausência de efeitos mediados pelo GH. Como os estrógenos orais estimulam a secreção de $\mathrm{GH}$, infere-se que alguns desses efeitos sobre o metabolismo das lipoproteínas sejam mediados por este $(8,100)$.

A proteína $\mathrm{C}$ reativa (PCR) é um marcador inflamatório fortemente associado com o risco de desenvolvimento de doença cardiovascular em ambos os sexos $(101,102)$. Existem evidências de que muitos marcadores inflamatórios sejam regulados pelos estrógenos. Ocorre aumento dos níveis séricos de PCR e de citoquinas pró-inflamatórias, como interleucina-6 (IL-6) e fator de necrose tumoral-alfa (TNF- $\alpha)$, durante a menopausa $(102,103)$. Estudos in vitro demonstraram que os estrógenos inibem diretamente a expressão do gene da IL- 6 e do TNF- $\alpha$, ambos secretados pelas células endoteliais, células da musculatura lisa vascular e monócitos/macrófagos (103).

Contudo, esses efeitos inibitórios dos estrógenos são conflitantes. Alguns estudos com mulheres pósmenopáusicas em terapia de substituição com estrógenos demonstraram níveis mais elevados de PCR nessas mulheres (104). O efeito desse tratamento é dependente da rota estrogênica, ocorrendo apenas com estrógenos administrados por via oral, provavelmente, por causa do efeito de primeira passagem hepática. Com isso, ocorre aumento na síntese hepática de PCR, que representa efeito indesejável do estrógeno oral, implicando na função vascular (104).

Existem fortes evidências de que o GH regule negativamente muitas citoquinas pró-inflamatórias. Os níveis séricos de PCR, IL-6 e TNF- $\alpha$ estão elevados em adultos com deficiência de $\mathrm{GH}$, sofrendo queda após o início do tratamento com $\mathrm{GH}(105,106)$. A produção monocitária de IL-6 e TNF- $\alpha$ está aumentada em pacientes com deficiência de GH e reduz após o início do tratamento com GH (106). Os níveis séricos de PCR estão baixos em pacientes com acromegalia e aumentam com o controle da doença (107). Esses dados demonstram que o $\mathrm{GH}$, direta ou indiretamente, reduz a inflamação, modulando os níveis séricos das citoquinas e os marcadores inflamatórios. Assim, pacientes hipogonádicas e GH-deficientes apresentam concentrações séricas elevadas de PCR, IL-6 e TNF- $\alpha(103,106)$.

\section{Implicações terapêuticas}

\section{Hipopituitarismo}

Nas mulheres com hipopituitarismo, a escolha da rota de administração estrogênica é importante porque elas são GH-deficientes e, por isso, já têm níveis baixos de IGF-1. Portanto, a via oral não deve ser a primeira escolha e sim a rota transdérmica $(31,58)$. Essas observações explicam porque alguns investigadores relataram níveis de IGF-1 mais baixos em pacientes com hipopituitarismo em relação aos homens, apesar de resposta similar ao teste de hipoglicemia insulínica. Entretanto, nenhum dos estudos comparou níveis de IGF-1 entre usuárias e não-usuárias de estrógenos (108-110).

As pacientes hipopituitárias são mais suscetíveis aos efeitos hepáticos da administração de estrógenos orais. O grau da supressão de IGF-1 pelos estrógenos orais é maior em pacientes $\mathrm{GH}$-deficientes do que em pacientes pós-menopáusicas (hipogonádicas e GH-suficientes). Assim, a administração de estrógenos orais pode agravar as anormalidades metabólicas e de composição corporal preexistentes e decorrentes do estado de deficiência de GH. Pelo mesmo motivo, as mulheres com síndrome de Laron (insensibilidade ao $\mathrm{GH}$ ) não devem usar estrógenos por administração oral (111).

\section{Terapia de reposição com $\mathrm{GH}$ no adulto}

\section{Níveis séricos de IGF-1}

Wolthers e cols. compararam as mudanças em IGF-1, na oxidação lipídica e no metabolismo protéico em pacientes com hipopituitarismo em tratamento com $\mathrm{GH}$, durante a administração de estrógenos oral e transdérmico. $\mathrm{O}$ tratamento com $\mathrm{GH}$ aumentou os níveis séricos de IGF-1, dependente da dose de GH, em ambos os grupos de tratamento com estrógenos. Todavia, a média dos valores de IGF-l foi significativamente menor durante o uso de estrógenos orais e em doses diferentes de GH. A oxidação lipídica pósprandial e a síntese protéica foram estimuladas pelo $\mathrm{GH}$, mas se mantiveram significativamente menores durante o tratamento com estrógenos orais. Dessa maneira, os estrógenos exercem atenuação da ação do $\mathrm{GH}$, dependentes da rota, em mulheres com deficiência de GH (31).

Diversos estudos têm relatado níveis menores de IGF-1 em mulheres GH-deficientes do que em homens, com doses similares de GH (112). Além disso, a dose de GH necessária para manter níveis adequados e 
comparáveis de IGF-1 é maior em mulheres do que em homens. Embora esses estudos não tenham análise do estado gonadal e da terapia estrogênica, presume-se que a menor sensibilidade ao $\mathrm{GH}$ nas mulheres advenha do uso concomitante do estrógeno oral, correspondendo à forma mais utilizada de estrógenos (113-116).

Cook, Ludlam e Cook observaram que a necessidade de GH em homens não foi diferente de mulheres que não estavam utilizando estrógenos, mas naquelas mulheres que estavam em uso de estrógenos orais a dose necessária de GH foi duas vezes maior (45).

Janssen e cols. relataram que a troca de estrógenos orais para estrógenos transdérmicos aumentou os níveis séricos de IGF-1 em 30\% durante o tratamento com $\mathrm{GH}(35)$.

\section{Composição corporal}

As mudanças de composição corporal ligadas ao gênero, em resposta à terapia com $\mathrm{GH}$ em adultos com hipopituitarismo, têm sido freqüentemente observadas por diversos autores, independente da técnica utilizada para medi-la $(112,113,117)$. Johannsson e cols. observaram que o aumento na massa gorda e na água corporal total foi mais marcado nos homens do que nas mulheres, bem como a redução na gordura corporal total (112).

Burman e cols. demonstraram, em um estudo de nove meses de seguimento, placebo-controlado, que a terapia com GH induziu, nos homens, maior redução da gordura corporal total e da gordura abdominal total do que nas mulheres, estimados por densitometria. A dose de GH foi igual em ambos os sexos (117).

As observações de que os estrógenos orais atenuam os efeitos do $\mathrm{GH}$, em relação ao anabolismo protéico e à utilização de lipídios, podem explicar parcialmente a redução da eficácia do tratamento com GH em mulheres com hipopituitarismo. Nos estudos citados anteriormente, a maioria das pacientes hipopituitárias estava utilizando estrógenos, embora a via de administração não tenha sido especificada. Entretanto, inferiu-se que a maioria desses estudos empregou a rota oral, por ser a via usual de administração. A maioria dos homens hipogonádicos também utilizou andrógenos nesses estudos, e a possibilidade de que eles poderiam amplificar as ações biológicas do GH não foi investigada $(112,113,117)$. Estudos com crianças com baixa estatura demonstraram que os andrógenos estimulam o crescimento de crianças $\mathrm{GH}$ deficientes durante a terapia com GH. Dessa maneira, o efeito regulatório positivo dos andrógenos deveria ser considerado como mecanismo adicional que explica o dismorfismo sexual na resposta ao $\mathrm{GH}$ (39).

\section{Implicações econômicas}

A observação de que os estrógenos orais atenuam os efeitos biológicos do GH tem implicações econômicas. O dobro da dose de GH foi necessário nas pacientes em terapia com estrógeno oral para manter os mesmos níveis de IGF- 1 que as mulheres em terapia transdérmica. Isso se aproxima à dose adicional de 1 UI $(0,3 \mathrm{mg})$ de $\mathrm{GH}$ ao dia, correspondendo ao custo de 4.400 dólares ao ano, por paciente. A prevalência de hipopituitarismo é estimada em 175 a 400 por 1 milhão, porquanto 50 a 120 mil adultos têm deficiência de GH, nos Estados Unidos. Desses adultos, metade são mulheres, e a maioria é tratada para o hipogonadismo coexistente. A redução de custo para a comunidade seria de 110 a 250 milhões dólares, se fosse substituída a rota oral pela transdérmica no tratamento concomitante do hipogonadismo gonadotrófico (118).

A via de administração transdérmica dos estrógenos, além de trazer mais custo-efetividade na ação do GH, também é a via recomendada pela Growth Hormone Research Society (119).

\section{CONCLUSÕES}

O tratamento do hipopituitarismo é complexo, oneroso e exige experiência clínica do médico e grande colaboração dos pacientes. $\mathrm{O}$ hipogonadismo feminino, na mulher adulta especialmente, necessita de abordagem detalhada, a fim de se obter a melhor e a mais fisiológica combinação de hormônios que possa corrigir adequadamente todas as deficiências presentes, sem acrescentar prejuízos à qualidade e à expectativa de vida dessas pacientes. Nesse sentido, a escolha dos hormônios, sua dose e a via de administração são aspectos fundamentais para a obtenção dos efeitos desejados, devendo-se preferir os estrógenos por via cutânea e os progestágenos derivados da 19-nortestosterona.

\section{REFERÊNCIAS}

1. Lamberts SW, Herder WW, van der Lely AJ. Pituitary insufficiency. Lancet. 1998;352:127-34.

2. van Aken MO, Lamberts SW. Diagnosis and treatment of hypopituitarism: an update. Pituitary. 2005;8(3-4):183-91. 
3. Abboud CF. Laboratory diagnosis of hypopituitarism. Mayo Clin Proc. 1986;61:35-48.

4. Bates AS, Van't Hoff W, Jones PJ, Clayton RN. The effect of hypopituitarism on life expectancy. J Clin Endocrinol Metab. 1996;81(3):1169-72.

5. Ascoli P, Cavagnini F. Hypopituitarism. Pituitary. 2006;9(4): 335-42.

6. Yen SS, Martin PL, Burnier AM, Czekala NM, Greaney MO Jr., Callantine MR. Circulating estradiol, estrone and gonadotropin levels following the administration of orally active 17betaestradiol in postmenopausal women. J Clin Endocrinol Metab. 1975;40(3):518-21.

7. Stevenson JC, Crook D, Godsland IF. Influence of age and menopause on serum lipids and lipoproteins in healthy women. Atherosclerosis. 1993;98(1):83-90.

8. Walsh BW, Schiff I, Rosner B, Greenberg L, Ravnikar V, Sacks FM. Effects of postmenopausal estrogen replacement on the concentrations and metabolism of plasma lipoproteins. $\mathrm{N}$ Engl J Med. 1991;325(17):1196-204.

9. The lipid research clinics coronary primary prevention trial results. II. The relationship of reduction in incidence of coronary heart disease to cholesterol lowering. JAMA. 1984;251(3): 365-74.

10. Kannel WB. High-density lipoproteins: epidemiologic profile and risks of coronary artery disease. Am J Cardiol. 1983; 52(4):B9-12.

11. Powers MS, Schenkel L, Darley PE, Good WR, Balestra JC, Place VA. Pharmacokinectics and pharmacodynamics of transdermal dosage forms of 17-Beta-estradiol: comparison with conventional oral estrogens used for hormone replacement. Am J Obstet Gynecol. 1985;152:1009-106.

12. Lobo RA. Effects of hormonal replacement on lipids and lipoproteins in postmenopausal women. J Clin Endocrinol Metab. 1991;73:925-30.

13. Rijpkema AHM, Van der Sanden AA, Ruijs AHC. Effects of postmenopausal oestrogen-progestogen replacement therapy on serum lipids and lipoproteins: a review. Maturitas. 1990;12:259-85

14. Hulley S, Grady D, Bush T, Furberg C, Herrington D, Riggs B, et al. Randomized trial of estrogen plus progestin for secondary prevention of coronary heart disease in postmenopausal women. Heart and Estrogen/progestin Replacement Study (HERS) Resarch Group. JAMA. 1998;280(7):605-13.

15. Grady D, Herrington D, Bittner V, Blumenthal R, Davidson M, Hlatky $\mathrm{M}$, et al. Cardiovascular disease outcomes during 6.8 years of hormone therapy: heart and estrogen/progestin Replacement Study follow-up (HERS II). JAMA. 2002;288(1): 49-57.

16. Hulley S, Furberg C, Barrett-Connor E, Cauley J, Grady D, Haskell W, et al. Noncardiovascular disease outcomes during 6.8 years of hormone therapy: heart and estrogen/progestin Replacement Study follow-up (HERS II). JAMA. 2002;288(1): 58-66.

17. Writing Group for the Women's Health initiative investigators. Risks and benefits of estrogen plus progestin in healthy postmenopausal women: principal results from the women's health initiative randomized controlled trial. JAMA. 2002;288(3): 321-33.

18. Million Women Study Collaborators. Breast cancer hormonereplacement therapy in the million women study. Lancet. 2003;362(9382):419-27.

19. The Women's Health Initiative Steering Committee. Effects of conjugated equine estrogen in postmenopausal women with hysterectomy: the women's health initiative randomized controlled trial. JAMA. 2004;291(14):1701-12.

20. Estrogen and progestogen use in peri- and postmenopausal women: September 2003 position statement of The North American Menopause Society. Menopause. 2003;10(6): 497-506.

21. North American Menopause Society. Recomendations for estrogen and progestogen use in peri- and postmenopausal women: october 2004 position statement of The North American Menopause Society. Menopause. 2004;11(6 Pt 1):589-600.

22. North American Menopause Society. Estrogen and progestogen use in peri- and postmenopausal women: march 2007 position statement of the North American Menopause Society. Menopause. 2007;14(2):168-82.

23. Bulow B, Hagmar L, Eskilsson J, Erfurth EM. Hypopituitary females have a high incidence of cardiovascular morbidity and an increased prevalence of cardiovascular risk factors. J Clin Endocrinol Metab. 2000;85(2):574-84.

24. Sesmilo G, Miller KK, Hayden D, Klibanski A. Inflammatory cardiovascular risk markers in women with hypopituitarism. $J$ Clin Endocrinol Metab. 2001;86(12):5774-81.

25. Utiger RD. Estrogen, thyroxine binding in serum, and thyroxine therapy. N Engl J Med. 2001;344(23):1784-5.

26. Arafah BM. Increased need for thyroxine in women with hypothyroidism during estrogen therapy. N Engl J Med. 2001; 344(23):1743-9.

27. van der Vange $\mathrm{N}$, Blankenstein MA, Kloosterboer HJ, Haspels AA, Thijssen JH. Effects of seven low-dose combined oral contraceptives on sex hormone binding globulin, corticosteroid binding globulin, total and free testosterone. Contraception. 1990;41(4):345-52.

28. Song S, Chen J, He M, Fotherby K. Effect of some oral contraceptives on serum concentrations of sex hormone binding globulin and ceruloplasmin. Contraception. 1989;39(4):385-99.

29. Wiegratz I, Kutschera E, Lee JH, Moore C, Mellinger U, Winkler $\mathrm{UH}$, et al. Effect of four different oral contraceptives on various sex hormones and serum-binding globulins. Contraception. 2003;67(1):25-32.

30. White T, Ozel B, Jain JK, Stanczyk FZ. Effects of transdermal and oral contraceptives on estrogen-sensitive hepatic proteins. Contraception. 2006;74(4):293-6.

31. Wolthers T, Hoffman DM, Nugent AG, Duncan MW, Umpleby $M$, Ho KK. Oral estrogen antagonizes the metabolic actions of growth hormone in growth hormone-deficient women. Am J Physiol Endocrinol Metab. 2001;281(6):E1191-6.

32. Hoffman DM, O'Sullivan AJ, Freund J, Ho KK. Adults with growth hormone deficiency have abnormal body composition but normal energy metabolism. J Clin Endocrinol Metab. 1995;80(1):72-7.

33. Salomon F, Cuneo RC, Hesp R, Sonksen PH. The effects of treatment with recombinant human growth hormone on body composition and metabolism in adults with growth hormone deficiency. N Engl J Med. 1989;321(26):1797-803.

34. Bellantoni MF, Vittone J, Campfield AT, Bass KM, Harman SM Blackman MR. Effects of oral versus transdermal estrogen on the growth hormone/insulin-like growth factor I axis in younger and older postmenopausal women: a clinical research center study. J Clin Endocrinol Metab. 1996;81(8):2848-53.

35. Janssen YJ, Helmerhorst F, Frolich M, Roelfsema F. A switch from oral ( $2 \mathrm{mg} /$ day) to transdermal ( 50 \{micro\}g/day) 17 \{beta\} estradiol therapy increases serum insulin-like growth factorlevels in recombinant human growth hormone $(\mathrm{GH})$-substituted women with GH deficiency. J Clin Endocrinol Metab. 2000;85(1):464-7. 
36. Weissberger AJ, Ho KK, Lazarus L. Contrasting effects of oral and transdermal routes of estrogen replacement therapy on 24-hour growth hormone (GH) secretion, insulin- like growth factor I, and GH-binding protein in postmenopausal women. J Clin Endocrinol Metab. 1991;72(2):374-81.

37. Heald A, Selby PL, White A, Gibson M. Progestins abrogate estrogen-induced changes in the insulin-like growth factor axis. Am J Obstet Gynecol. 2006;183(3):593-600.

38. Leung KC, Johannsson G, Leong GM, Ho KK. Estrogen regulation of growth hormone action. Endocr Rev. 2004;25(5):693-721.

39. Bourguignon JP. Linear growth as a function of age at onset of puberty and sex steroid dosage: therapeutic implications. Endocr Rev. 1988;9:467-88.

40. Ho KY, Evans WS, Blizzard RM, Veldhuis JD, Merriam GR, Samojlik E, et al. Effects of sex and age on the 24-hour profile of growth hormone secretion in man: importance of endogenous estradiol concentrations. J Clin Endocrinol Metab. 1987;64(1):51-8.

41. Baumann G. Growth hormone binding protein. J Pediatr Endocrinol Metab. 2001;14(4):355-75.

42. Kelly JJ, Rajkovic IA, O'Sullivan AJ, Sernia C, Ho KK. Effects of different oral oestrogen formulations on insulin-like growth factor-l, growth hormone and growth hormone binding protein in post-menopausal women. Clin Endocrinol (Oxf). 1993;39(5):561-7.

43. O'Sullivan AJ, Hoffman DM, Ho KK. Estrogen, lipid oxidation, and body fat. N Engl J Med. 1995;333(10):669-70.

44. Helle SI, Omsjo IH, Hughes SC, Botta L, Huls G, Holly JM, et al. Effects of oral and transdermal oestrogen replacement therapy on plasma levels of insulin-like growth factors and IGF binding proteins 1 and 3: a cross-over study. Clin Endocrinol (Oxf). 1996;45(6):727-32.

45. Cook DM, Ludlam WH, Cook MB. Route of estrogen administration helps to determine growth hormone $(\mathrm{GH})$ replacement dose in GH-deficient adults. J Clin Endocrinol Metab. 1999;84(11):3956-60.

46. Friend KE, Hartman ML, Pezzoli SS, Clasey JL, Thorner MO. Both oral and transdermal estrogen increase growth hormone release in postmenopausal women: a clinical research center study. J Clin Endocrinol Metab. 1996;81(6):2250-6.

47. Copeland KC. Effects of acute high dose and chronic low dose estrogen on plasma somatomedin- $C$ and growth in patients with Turner's syndrome. J Clin Endocrinol Metab. 1988;66(6): 1278-82.

48. wson-Hughes B, Stern D, Goldman J, Reichlin S. Regulation of growth hormone and somatomedin-C secretion in postmenopausal women: effect of physiological estrogen replacement. J Clin Endocrinol Metab. 1986;63(2):424-32.

49. Murphy LJ, Friesen HG. Differential effects of estrogen and growth hormone on uterine and hepatic insulin-like growth factor I gene expression in the ovariectomized hypophysectomized rat. Endocrinology. 1988;122(1):325-32.

50. Nugent AG, Leung KC, Sullivan D, Reutens AT, Ho KK. Modulation by progestogens of the effects of oestrogen on hepatic endocrine function in postmenopausal women. Clin Endocrinol (Oxf). 2003;59(6):690-8.

51. Heald A, Selby PL, White A, Gibson M. Progestins abrogate estrogen-induced changes in the insulin-like growth factor axis. Am J Obstet Gynecol. 2000;183(3):593-600.

52. Bellantoni MF, Harman SM, Cho DE, Blackman MR. Effects of progestin-opposed transdermal estrogen administration on growth hormone and insulin-like growth factor-l in postmenopausal women of different ages. J Clin Endocrinol Metab. 1991;72(1):172-8.
53. Karjalainen A, Paassilta M, Heikkinen J, Backstrom AC, Savolainen M, Kesaniemi YA. Effects of peroral and transdermal oestrogen replacement therapy on glucose and insulin metabolism. Clin Endocrinol (Oxf). 2001;54(2):165-73.

54. Goebelsmann U, Mashchak CA, Mishell DR. Comparision of hepatic impact of oral and vaginal administration of ethinyl estradiol. Am J Obstet Gynecol. 1985;151:868-77.

55. Mashchak CA, Lobo RA, Dozono-Takano R, Eggena P, Nakamura RM, Brenner PF, et al. Comparison of pharmacodynamic properties of various estrogen formulations. Am J Obstet Gynecol. 1982;144(5):511-8.

56. Baxter RC. Circulation binding proteins for the insulin-like growth factors. Trends Endocrinol Metab. 1993;4:91-6.

57. Chin E, Zhou J, Dai J, Baxter RC, Bondy CA. Cellular localization and regulation of gene expression for components of the insulin-like growth factor ternary binding protein complex. Endocrinology. 1994;134(6):2498-504.

58. Kam GY, Leung KC, Baxter RC, Ho KK. Estrogens exert routeand dose-dependent effects on insulin-like growth factor (IGF)binding protein- 3 and the acid-labile subunit of the IGF ternary complex. J Clin Endocrinol Metab. 2000;85(5):1918-22.

59. Cano A, Castelo-Branco C, Tarín JJ. Effect of menopause and different combined estradiol-progestin regimens on basal and growth hormone-releasing hormone-stimulated serum growth hormone, insulin-like growth factor-1, insulin-like growth factor binding protein (IGFBP)-1, and IGFBP-3 levels. Fertil Steril. 1999;71(2):261-7.

60. Garnero P, Tsouderos Y, Marton I, Pelissier C, Varin C, Delmas PD. Effects of intranasal 17\{beta\}-estradiol on bone turnover and serum insulin-like growth factor I in postmenopausal women. J Clin Endocrinol Metab. 1999;84(7):2390-7.

61. Lewitt MS, Denyer GS, Cooney GJ, Baxter RC. Insulin-like growth factor-binding protein-1 modulates blood glucose levels. Endocrinology. 1991;129(4):2254-6.

62. Paassilta M, Karjalainen A, Kervinen K, Savolainen MJ, Heikkinen J, Backstrom AC, et al. Insulin-like growth factor binding protein-1 (IGFBP-1) and IGF-1 during oral and transdermal estrogen replacement therapy: relation to lipoprotein(a) levels. Atherosclerosis. 2000;149(1):157-62.

63. Rajaram S, Baylink DJ, Mohan S. Insulin-like growth factorbinding proteins in serum and other biological fluids: regulation and functions. Endocr Rev. 1997;18(6):801-31.

64. Tapanainen P, Risteli L, Knip M, Kaar ML, Risteli J. Serum aminoterminal propeptide of type III procollagen: a potential predictor of the response to growth hormone therapy. J Clin Endocrinol Metab. 1988;67(6):1244-9.

65. Hassager C, Jensen LT, Podenphant J, Thomsen K, Christiansen C. The carboxy-terminal pyridinoline cross-linked telopeptide of type I collagen in serum as a marker of bone resorption: The effect of nandrolone decanoate and hormone replacement therapy. Calcif Tissue Int. 1994;54(1):30-3.

66. Rechler MM, Nissley SP, Podskalny JM, Moses AC, Fryklund L. Identification of a receptor for somatomedin-like polypeptides in human fibroblasts. J Clin Endocrinol Metab. 1977;44(5):820-31.

67. Bennett A, Chen T, Feldman D, Hintz RL, Rosenfeld RG. Characterization of insulin-like growth factor I receptors on cultured rat bone cells: regulation of receptor concentration by glucocorticoids. Endocrinology. 1984;115(4):1577-83.

68. Hock JM, Centrella M, Canalis E. Insulin-like growth factor I has independent effects on bone matrix formation and cell replication. Endocrinology. 1988;122(1):254-60.

69. Ho K, Weissberger AJ. Impact of short-term estrogen administration on growth hrmone secretion and action: distint route- 
dependent effects on connective and bone tissue metabolism. J Bone Miner Res. 1992;7:821-7.

70. Yakar S, Liu JL, Stannard B, Butler A, Accili D, Sauer B, et al. Normal growth and development in in the absence of hepátic insulin-like growth factor I. Proc Natl Acad Sci U S A. 1999;96(13):7324-9.

71. Wynn V, Adams PW, Godsland I, Melrose J, Niththyananthan R, Oakley NW, et al. Comparison of effects of different combined oral-contraceptive formulations on carbohydrate and lipid metabolism. Lancet. 1979;1(8125):1045-9.

72. Kasdorf G, Kalkhoff RK. Prospective studies of insulin sensitivity in normal women receiving oral contraceptive agents. $J$ Clin Endocrinol Metab. 1988;66(4):846-52.

73. Cagnacci A, Soldani R, Carriero PL, Paoletti AM, Fioretti P, Melis GB. Effects of low doses of transdermal 17 beta-estradiol on carbohydrate metabolism in postmenopausal women. J Clin Endocrinol Metab. 1992;74(6):1396-400.

74. De Cleyn K, Buytaert P, Coppens M. Carbohydrate metabolism during hormonal substitution therapy. Maturitas. 1989;11:235-42.

75. Ajabor LN, Tsai CC, Vela P, Yen SS. Effect of exogenous estrogen on carbohydrate metabolism in postmenopausal women. Am J Obstet Gynecol. 1972;113(3):383-7.

76. Nabulsi AA, Folsom AR, White A, Patsch W, Heiss G, Wu KK, et al. Association of hormone-replacement therapy with various cardiovascular risk factors in postmenopausal women. The Atherosclerosis Risk in Communities Study Investigators. N Engl J Med. 1993;328(15):1069-75.

77. O'Sullivan AJ, Ho KK. A comparison of the effects of oral and transdermal estrogen replacement on insulin sensitivity in postmenopausal women. J Clin Endocrinol Metab. 1995;80(6):1783-8.

78. Perseghin G, Scifo P, Pagliato E, Battezzati A, Benedini S, Soldini $L$, et al. Gender factors affect fatty acids-induced insulin resistance in nonobese humans: effects of oral steroidal contraception. J Clin Endocrinol Metab. 2001;86(7):3188-96.

79. Godsland IF, Walton C, Felton C, Proudler A, Patel A, Wynn V. Insulin resistance, secretion, and metabolism in users of oral contraceptives. J Clin Endocrinol Metab. 1992;74(1):64-70.

80. Balogh A, Kauf E, Vollanth R, Graser G, Klinger G, Oettel M. Effects of two oral contraceptives on plasma levels of insulinlike-growth factor I (IGF-1) and growth hormone. Contraception. 2000;259-69.

81. Jorgensen JOL, Theusen L, Ingemann-Hansen T, Pedersen SA, Jorgensen J, Christiansen JS. Beneficial effects of growth hormone treatment on $\mathrm{GH}$-deficient adults. Lancet. 1989;1:1221-5.

82. Salomon F, Cuneo RC, Hesp R, Sonksen PH. The effects of treatment with recombinant human growth hormone on body composition and metabolism in adults with growth hormone deficiency. N Engl J Med. 1989;321(26):1797-803.

83. Moller N, Jorgensen JO, Alberti KG, Flyvbjerg A, Schmitz O. Short-term effects of growth hormone on fuel oxidation and regional substrate metabolism in normal man. J Clin Endocrinol Metab. 1990;70(4):1179-86.

84. O'Sullivan AJ, Crampton LJ, Freund J, Ho KK. The route of estrogen replacement therapy confers divergent effects on substrate oxidation and body composition in postmenopausal women. J Clin Invest. 1998;102(5):1035-40.

85. Ockner RK, Lysenko N, Manning JA, Monroe SE, Burnett DA. Sex esteroid modulation of fatty acid utilization and fatty acid binding protein concentration in rat liver. J Clin Invest. 1980;65:1013-23.
86. Walsh BW, Schiff I, Rosner B, Greenberg L, Ravnikar V, Sacks FM. Effects of postmenopausal estrogen replacement on the concentrations and metabolism of plasma lipoproteins. $\mathrm{N}$ Engl J Med. 1991;325(17):1196-204.

87. Haarbo J, Marslew U, Gotfredsen A, Christiansen C. Postmenopausal hormone replacement therapy prevents central distribution of body fat after menopause. Metabolism. 1991;40:1323-6.

88. Troisi RJ, Wolf AM, Mason JE, Klinger KM, Colditz GA. Relation of body fat distribution to reproductive factors in pre- and postmenopausal women. Obes Res. 1995;3:143-51.

89. Kritz-Silverstein D, Barret-Connor E. Long-term postmenopausal hormone use, obesity and fat distribuition in older women. JAMA. 1996; 275:46-9.

90. Effects of estrogen or estrogen/progestin regimes on heart disease risk factors in postmenopausal women. The Postmenopausal Estogen/Progestin Interventions (PEPI) Trial. The Writing Group for the PEPI Trial. JAMA. 1995;273(3):199-208.

91. Wing RR, Mathews KA, Kuller LH, Meilahn EN, Plantinga PL. Weight gain at the time of menopause. Arch Intern Med. 1991;151:97-102.

92. Aloia JF, Vaswani A, Russo L, Sheehan M, Flaster E. The influence of menopause and hormonal replacement therapy on body cell mass and body fat mass. Am J Obstet Gynecol. 1995;172:896-900.

93. Gambacciani M, Ciaponi M, Cappagli B, Piaggesi L, De Simone $L$, Orlandi R, et al. Body weight, body fat distribution, and hormonal replacement therapy in early postmenopausal women. J Clin Endocrinol Metab. 1997;82(2):414-7.

94. Hew FL, Alford FP, Christopher M, Rantzau C, Koschmann M, O'Neal D, et al. Effects of growth hormone deficiency and therapy in adults on skeletal muscle glucose metabolism, lipid profiles and regional body composition. Endocrinol Metab. 1996;3(Suppl 1):55-60.

95. Seed M. Sex hormones, lipoproteins and cardiovascular risk. Atherosclerosis. 1990;90:1-7.

96. Rudling M, Olivecrona H, Eggertsen G, Angelin B. Regulation of rat hepatic low density lipoprotein receptors. In vivo stimulation by growth hormone is not mediated by insulin-like growth factor-I. J Clin Invest. 1996;97:292-9.

97. Rudling $M$, Norstedt G, Olivecrona $H$, Reihnér E, Gustafsson JA, Angelin B. Importance of growth hormone for the induction of hepatic low density lipoprotein receptors. Proc Natl Acad Sci U S A. 1992;89:6983-7.

98. Elam MB, Wilcox HG, Solomon SS, Heimberg M. In vivo growth hormone treatment stimulates secretion of very low density lipoprotein by the isolated perfused rat liver. Endocrinology. 1992;131(6):2717-22.

99. Edén S, Wiklund O, Oscarsson J, Rosén T, Bengtsson BA. Growth hormone treatment of growth hormone-deficient adults results in a marked increased in Lp(a) and HDL cholesterol concentrations. Arterioscler Thromb Vasc Biol. 1993;13:296-301.

100. Godsland I. Effects of postmenopausal hormone replacement on lipid, lipoprotein and apolipoprotein (a) concentrations: analysis of studies published from 1974-2000. Fertil Steril. 2001;75:898-915.

101. Ridker PM, Cushman M, Stampfer MJ, Tracy RP, Hennekens $\mathrm{CH}$. Inflammation, aspirin, and the risk of cardiovascular disease in apparently healthy men. $\mathrm{N}$ Engl $\mathrm{J}$ Med. 1997;336(14):973-9.

102. Ridker PM, Hennekens $\mathrm{CH}$, Buring JE, Rifai N. C-reactive protein and other markers of inflammation in the prediction of cardiovascular disease in women. $N$ Engl J Med. 2000;342(12):836-43. 
103. Pfeilschifter J, Koditz R, Pfohl M, Schatz H. Changes in proinflammatory cytokine activity after menopause. Endocr Rev. 2002;23(1):90-119.

104. Cushman M, Meilahn EN, Psaty BM, Kuller LH, Dobs AS, Tracy RP. Hormone replacement therapy, inflammation and hemostasis in elderly women. Arterioscler Thromb Vasc Biol. 1999;19:893-9.

105. Sesmilo G, Biller BM, Llevadot J, Hayden D, Hanson G, Rifai $\mathrm{N}$, et al. Effects of growth hormone administration on inflammatory and other cardiovascular risk markers in men with growth hormone deficiency. A randomized, controlled clinical trial. Arch Intern Med. 2000;133:111-22.

106. Serri O, St-Jacques P, Sartippour M, Renier G. Alterations of monocyte function in patients with growth hormone (GH) deficiency: effect of substitutive GH therapy. J Clin Endocrinol Metab. 1999;84(1):58-63.

107. Sesmilo G, Fairfield WP, Katznelson L, Pulaski K, Freda PU, Bonert $\mathrm{V}$, et al. Cardiovascular risk factors in acromegaly before and after normalization of serum IGF-I levels with the $\mathrm{GH}$ antagonist pegvisomant. J Clin Endocrinol Metab. 2002;87(4):1692-9.

108. Svensson J, Johannsson G, Bengtsson BA. Insulin-like growth factor-l in growth hormone-deficient adults: relationship to population-based normal values, body composition and insulin tolerance test. Clin Endocrinol (Oxf). 1997;46(5):579-86.

109. Mukherjee A, Monson JP, Jonsson PJ, Trainer PJ, Shalet SM. Seeking the optimal target range for insulin-like growth factor I during the treatment of adult growth hormone disorders. J Clin Endocrinol Metab. 2003;88(12):5865-70.

110. Hilding A, Hall K, Wivall-Helleryd IL, Saaf M, Melin AL, Thoren M. Serum levels of insulin-like growth factor I in 152 patients with growth hormone deficiency, aged 19-82 years, in relation to those in healthy subjects. J Clin Endocrinol Metab. 1999;84(6):2013-9.

111. Gibney J, Johannsson G, Leung KC, Ho KK. Comparison of the metabolic effects of raloxifene and oral estrogen in postmenopausal and growth hormone-deficient women. J Clin Endocrinol Metab. 2005;90(7):3897-903.

112. Johannsson G, Bjarnason R, Bramnert M, Carlsson LM, Degerblad $\mathrm{M}$, Manhem $\mathrm{P}$, et al. The individual responsiveness to growth hormone (GH) treatment in GH- deficient adults is dependent on the level of GH-binding protein, body mass index, age, and gender. J Clin Endocrinol Metab. 1996;81(4):1575-81.
113. Gotherstrom G, Svensson J, Koranyi J, Alpsten M, Bosaeus I, Bengtsson B, et al. A prospective study of 5 years of $\mathrm{GH}$ replacement therapy in $\mathrm{GH}$-deficient adults: sustained effects on body composition, bone mass, and metabolic indices. J Clin Endocrinol Metab. 2001;86(10):4657-65.

114. Johannsson G, Rosen T, Bengtsson BA. Individualized dose titration of growth hormone $(\mathrm{GH})$ during $\mathrm{GH}$ replacement in hypopituitary adults. Clin Endocrinol (Oxf). 1997;47(05):571-81.

115. Bengtsson BA, Abs R, Bennmarker H, Monson JP, Feldt-Rasmussen $U$, Hernberg-Stahl E, et al. The effects of treatment and the individual responsiveness to growth hormone (GH) replacement therapy in $665 \mathrm{GH}$-deficient adults. KIMS Study Group and the KIMS International Board. J Clin Endocrinol Metab. 1999;84(11):3929-35.

116. Drake WM, Coyte D, Camacho-Hubner C, Jivanji NM, Kaltsas G, Wood DF, et al. Optimizing growth hormone replacement therapy by dose titration in hypopituitary adults. J Clin Endocrinol Metab. 1998;83(11):3913-9.

117. Burman P, Johansson AG, Siegbahn A, Vessby B, Karlsson FA. Growth hormone (GH)-deficient men are more responsive to $\mathrm{GH}$ replacement therapy than women. J Clin Endocrinol Metab. 1997;82(2):550-5.

118. Rosen T, Bengtsson BA. Epidemiology of adult onset hypopituitarism in Gotemburg, Sweden during 1956-1987. Proc International Symposium on Growth Hormone and Growth Factors, 60; 1994.

119. Consensus guidelines for the diagnosis and treatment of adults with growth hormone deficiency: summary statement of the growth hormone research society workshop on adult growth hormone deficiency. J Clin Endocrinol Metab. 1998;83(2):379-81.

\section{Endereço para correspondência:}

Mauro Antônio Czepielewski

Serviço de Endocrinologia do Hospital de Clínicas de Porto Alegre

Rua Ramiro Barcelos 2350, prédio 12, $4^{\circ}$ andar

90035-003 Porto Alegre, RS

E-mail: maurocze@terra.com.br 